\author{
A. Szoka ${ }^{1}$, G. Gajowiec ${ }^{1}$, A. Zieliński ${ }^{1 *}$, W. Serbiński ${ }^{1}$, J.-M. Olive ${ }^{2}$, A. Ossowska ${ }^{1}$ \\ ${ }^{1}$ Gdansk University of Technology, Faculty of Mechanical Engineering, Department of \\ Materials Engineering and Bonding, 11/12 Narutowicza, 80-233 Gdańsk, Poland \\ ${ }^{2}$ Universite de Bordeaux, Institute de Mecanique et des Materiaux, 33000 Bordeaux, France \\ *azielins@pg.gda.pl
}

\title{
HYDROGEN DEGRADATION OF PRE-OXIDIZED ZIRCONIUM ALLOYS
}

\begin{abstract}
The presence of the oxide layers on $\mathrm{Zr}$ alloys may retard or enhance the hydrogen entry and material degradation, depending on the layer features. This research has been aimed to determine the effects of preoxidation of the Zircaloy-2 alloy at a different temperature on hydrogen degradation. The specimens were oxidised in laboratory air at $350^{\circ} \mathrm{C}, 700^{\circ} \mathrm{C}$, and $900^{\circ} \mathrm{C}$. After, some samples were tensed at $10-5$ strain rate and simultaneously charged with hydrogen under constant direct voltage in $1 \mathrm{~N}$ sulfuric acid at room temperature. Other specimens were charged without any tension, then annealed at $400^{\circ} \mathrm{C}$ for $4 \mathrm{~h}$ and finally tensed at above strain rate. The SEM examinations were performed on the cross-sections and fracture faces of specimens. The obtained results demonstrate the effects of the oxide layer on the cathodic current and hydrogen entry, mechanical properties and the appearance of hydrides and fracture behaviour.
\end{abstract}

Keywords: zirconium alloys, oxidation, hydrogen degradation, slow strain rate tests, cathodic hydrogen charging

\section{INTRODUCTION}

\section{Background}

Zirconium alloys are widely used in chemical and nuclear industries because of their excellent mechanical and corrosion properties, and their low neutron absorption under operational conditions. They are applied as fuel cladding tubes and other structural elements in light water reactors [1]. The zirconium alloys used in nuclear industry include $\mathrm{Zr}-\mathrm{Sn}$ and $\mathrm{Zr}-\mathrm{Nb}$ alloys. The nuclear accidents such as loss of coolant accident (LOCA) and reactivity initiated accidents (RIA) may result in degradation of fuel claddings associated with hydrogen appearance, entry into the metal and its degradation. The excessive oxidation at high temperatures can cause the breakaway of the oxide layer can and formation of the easy hydrogen diffusion channels [1,2]. Both phenomena are related to each other by the manner not fully recognized by now. 


\section{Oxidation}

The oxidation process takes place through two steps and layers. Like the first, a layer of dense tetragonal $\beta$-zirconia is formed and then it transforms progressively to an fcc $\alpha$-zirconia external layer [3]. The transformation temperature depends on an alloy composition and oxidizing environment. The oxide films fabricated hydrothermally on $\mathrm{Zr}$ alloys may have monoclinic $\mathrm{ZrO}_{2}$ structure even at $200^{\circ} \mathrm{C}$ after $24 \mathrm{~h}$ of treatment [4]. In another research on the Zircaloy-4, the monoclinic and the tetragonal phases were formed already at $350^{\circ} \mathrm{C}$ temperature [5]. At temperatures of $950-1200^{\circ} \mathrm{C}$ both crystallographic structures of an oxide phase may be still present [6]. Both phases may then appear at moderate temperatures.

The layer oxide was observed to compose of two zones, the outer one being porous, the inner one more dense and defective [4]. The sub-stoichiometric zirconium oxide captured the oxygen atoms from near stoichiometric tin oxides or niobium oxides, and the reduction of tin ions caused the protection loss of the inner layer. The oxide layer was observed to be microcrystalline, growing into columnar grains [7]. The mean crystallite size increased at increasing oxide thickness. The more complex layer structure at a different stage of oxidation was also reported [8]; the interface exhibited an intermediate ZrO layer, a discontinuous layer of "blocky" $\mathrm{Zr}_{3} \mathrm{O}$ grains embedded in the $\mathrm{ZrO}$ layer, and a suboxide layer appeared being an oxygen saturated solid solution in the metal matrix. A protective oxide layer according to [9] is composed of monoclinic $\mathrm{ZrO}_{2}$ and a small amount of tetragonal $\mathrm{ZrO1} .88$, which acts as a very effective diffusion barrier.

The destabilization of the oxide layer may occur by a different mechanism: cracking of the oxide resulting from the transformation of tetragonal to the monoclinic structure (breakaway phenomenon); cracking of the oxide as a result of the accumulation of compressive stresses followed the volume expansion attendant upon oxide formation; porosity formed in the oxide. The appearance of breakaway oxidation depends on temperature, environment and alloy composition. The breakaway oxidation in steam (without nitrogen) occurs at temperatures up to $1300 \mathrm{~K}$ [10] and after time ranged between 2400 and $5500 \mathrm{~s}$ [6]. In other research on the same alloy, the oxide layer was indeed compact at $1200^{\circ} \mathrm{C}$, even if the oxide scale formed at $1000^{\circ} \mathrm{C}$ indicated breakaway phenomena [11]. Oxides grown on pure zirconium were less permeable that those on multiphase alloys because of a greater number of grain boundaries, interfaces and diffusion pathways [12]. Significant differences between the alloys were found in the temperature range $870-1320 \mathrm{~K}$, and the breakaway of Zircaloy-4 was reported to be significant at $1000^{\circ} \mathrm{C}$ and above [13].

The oxidation in air is strongly influenced by the breakaway effect, as the nitrogen diffusion through cracks to the metal-oxide interface results in nitride formation $[1,13]$. The oxide layer may be then be degraded by local inclusions of zirconium nitride. Finally, the porosity may increase breaking up the coherent microstructure of the oxide scale and result again in the oxide breakaway. These effects become important under conditions of oxygen starvation. The inclusions showed a tendency for nitrogen to displace some oxygen atoms within the oxide layer, degrading the oxide scale integrity and promoting further oxidation [10]. Oxygen can be then considered as an active species and nitrogen as a catalyst that promotes breakaway [14]. Formation of the zirconium nitride phase in the oxide near the metal-oxide boundary increased up to $1473 / 1573 \mathrm{~K}$ [1]. A mixed $\mathrm{ZrO}_{2} / \mathrm{ZrN}$ zone in the samples was seen at 973 and $1073 \mathrm{~K}$ for Zircaloy-4, resulting in very porous and thick oxide scales. However, at $1673 \mathrm{~K}$, Zircaloy-4 exhibited a dense oxide scale and no evidence of formation of $\mathrm{ZrN}$ at the metal-oxide boundary.

Pre-oxidation retards or even prevents the attack of nitrogen and, hence, leads to slower oxidation kinetics in the air compared to tests without pre-oxidation. As long as the oxide 
scale is dense, no transport of nitrogen to the metal is possible. Only after formation of cracks nitrogen may contribute to the degradation phenomenon, but the acceleration of the reaction is delayed compared to that for no pre-oxidized alloy [1]. However, in the tests performed in the MOZART facility [15], pre-oxidation at low temperatures made faster the breakaway oxidation in air. In the quench test, the pre-oxide and absorbed hydrogen did not affect the high-temperature oxidation [16]. In comparison with steam, chemical heat release during oxidation in the air was higher by $80 \%$, which may lead to a more rapid escalation of the nuclear accident. The barrier effect of the cladding against the release of fission products was presumed to be lost earlier in the air compared to steam [1].

\section{Hydrogen degradation}

Hydrogen may appear in zirconium alloys in an interstitial solution of zirconium, hydrogen bonded by weak (dislocations, vacancies, $\mathrm{O}$ atoms) or strong traps (interfaces of inclusions), and as hydrides. The interstitial solubility is strongly dependent on temperature and ranges between $50 \mathrm{ppm}$ at room temperature to even 50 wt pct at 1000-1300K [18]. Maximum hydrogen contents of $\mathrm{H} / \mathrm{Zr}=0.9$ were obtained for the lowest temperatures, and highest partial pressures investigated [19]. The diffusivity of $\mathrm{H}$ in $\mathrm{Zr}$ equals to $5.46810^{-7} \exp (-45293 / \mathrm{RT}) \mathrm{m}^{2} / \mathrm{s}$ [20]. The previous hydrogen solubility and diffusion data are a little diverse [21].

Two stable hydride phases, $\delta$-hydride (fcc) and $\varepsilon$-hydride (fct), and at least one metastable phase, $\gamma$-hydride (fct) may appear at different temperature and hydrogen content [22]. The $\delta$-hydride phase was found to be the predominant at hydrogen content up to $1250 \mathrm{wt}$ ppm, at about $3000 \mathrm{wt}$ ppm of hydrogen a significant amount of $\gamma$-hydride was observed, and at the highest hydrogen content, over $6000 \mathrm{wt}$ ppm, the $\varepsilon$-hydride phase appeared [23]. The hydrides observed in fuel cladding exposed to reactor environment were the most often fcc $\delta$ hydride $\mathrm{ZrH}_{1.6}$ [7]. The intergranular hydrides had a stronger effect on ductility than the intragranular ones [24]. At high cooling rates or large matrix grains, a predominance of intragranular hydrides was observed, while lower cooling rates or small grain sizes produced more intergranular or grain boundary hydrides. The macro-hydride orientation was significantly influenced by applied stresses; compressive forces reoriented hydrides with their normal perpendicular to the loading direction [25].

The $\mathrm{Zr}$ alloys are either strengthened or softened by hydrogen, depending on temperature and hydrogen content [26]. Hydrides as reported in [25] always degraded the tensile strength, ductility and fracture toughness. The softening can be attributed to the interstitial hydrogen solution [27]. The Young's modulus and the shear modulus of the zirconium hydrogen solid solution decreased with increasing hydrogen content. The microhardness of solid zirconium solution was reduced by hydrogen addition [28]. The ductility of solid zirconium solution increased with hydrogen addition. In [29] the elongation and ductility were reported to decrease significantly with increasing hydrogen content, but the room temperature strength slightly increased. The hydrogen-reduced the fracture toughness [7]. The fracture strains decreased rapidly with increasing hydride blister/layer depth to levels of about $100 \mu \mathrm{m}$ deep and then remained roughly constant [30]. As the hydrogen content increased, an increase in the strength, a decrease in the ductility and the maximum stress were observed with increasing hydrogen content for Zircaloy-4 [31]. The ductility at room temperature decreased with increasing hydrogen content [26]. The room temperature strength of $\mathrm{Zr}-\mathrm{Sn}-\mathrm{Fe}-\mathrm{Nb}$ tubes increased slightly, and the ductility decreased with the formation of the hydrides [32]. The loss of ductility in the presence of circumferential hydrides was associated with the secondary cracking during the final process of the fracture. When studying the $\mathrm{Zr}-\mathrm{Nb}$ tubes charged 
with hydrogen at elevated temperature and quenched, the ultimate tensile stresses and plastic elongations decreased drastically when the cooling rate was reduced [33]. Hydrogen concentration had a weak effect on mechanical characteristics in comparison to the temperature influence; only fracture stress for hydrogen containing specimens was considerably higher, and the modulus of elasticity increased in the range of $20-200^{\circ} \mathrm{C}$ [34].

The fracture behavior was also dependent on the presence of hydrides. The solid solution $\mathrm{H}$ atoms resulted in a ductile fracture, on the contrary to $\mathrm{ZrH}_{2}$ precipitate [35]. The asreceived (non-oxidized) samples were completely plastic, and they deformed without cracking in the ring compression test. For the specimen containing $220 \mathrm{ppm} \mathrm{H}$, at $25^{\circ} \mathrm{C}$, almost completely brittle behavior was observed [36]. A dimple fracture was normally seen in the asreceived specimens, whereas some cracks across the zirconium matrix appeared at $300 \mathrm{wt}$ ppm of hydrogen. In the case of the $700 \mathrm{ppm}$ charged specimen, a brittle fracture was a dominating mechanism with secondary cracks found on the fracture surface. Such secondary cracks along the platelets of hydrides were also observed on the fracture surfaces of tubes [32]. In [27], the cleavage facets were observed on the fracture surface of unalloyed $\mathrm{Zr}$ and a mixture of dimple and cleavage facets for the $\mathrm{Nb}$-containing alloys. At the grain size below $30 \mu \mathrm{m}$, the cracks were small and independent, while above $500 \mu \mathrm{m}$ they became larger and propagated along the radial direction. Not only large cracks but also small bulges were observed [37]. The ductile fracture showed some dimples associated with ductile metallic ligaments [17]. However, in another research, except for some specimens with high $\mathrm{H}$ concentration at room temperature, the macroscopic fracture behaviour was ductile [38]. For specimens possessing the circumferential hydrides, the fracture was ductile. Transverse fracture of the circumferential hydrides produced a much smaller fractured area than the lengthwise fracture of the radial hydrides under the tensile hoop stress state [33].

The hydrogen degradation mechanism is still discussed. Hydrogen-induced decohesion was considered as the main mechanism explaining the loss of ductility at medium and high hydrogen contents. Cracks can easily propagate through the hydrides between two Zr atomic layers [39]. Hydrogen-induced decohesion and the volume misfit between the $\mathrm{Zr}$ and hydride phases can create the sufficient stress for fracture. In [40], the hydrogen-induced embrittlement of the hcp Zr matrix was not confirmed, and hydrogen fracture in the presence of hydrides was attributed to the brittle nature of hydrides. The hydride presence was also postulated [41] to create a hydrogen concentration gradient, where the bulk concentration was greater than that at the crack tip. This concentration gradient was considered as the driving force for diffusion of hydrogen to the crack tip and subsequent hydride growth. Predominantly grain boundary hydrides were observed. According to [35], hydrogen atoms at low contents could help in dislocation multiplication, following the hydrogen-enhanced localized plasticity mechanism. At high contents, the dislocations and cracks could nucleate from precipitate - matrix interface, indicating the decohesion mechanism as a primary method for $\mathrm{Zr}$ degradation.

\section{Oxides and hydrogen entry}

There is few data on hydrogen solubility and diffusion in the oxide layers. The hydrogen dissolution in monoclinic $\mathrm{ZrO}$ oxide at $500-1100^{\circ} \mathrm{C}$ temperatures in oxygen/water vapor atmosphere ranged from $10^{-5}$ to $10^{-4} \mathrm{~mol} \mathrm{H} / \mathrm{mol}$ oxide and decreased with increasing temperature [42]. The hydrogen uptake in the initial phase controlled by hydrogen diffusion through the growing oxide layer was proportional to $\mathrm{t}^{3 / 8}$ [43]. Hydrogen content in alloys oxidized at high dissolved oxygen (DO) conditions was invariably lower than that obtained at low DO conditions [44]. 
The perfect oxide itself presents an effective barrier to the absorption of hydrogen. An initially high hydrogen absorption rate may decrease with increasing oxide thickness up to the oxide phase transition region [7]. Enrichment of hydrogen along oxide boundaries together with porosity networks around particles and oxide interfaces were observed. The pores were local reduction sites where $\mathrm{H}_{2}$ evolved on transition metal sites [45]. In [46] the effect of precharging on oxidation was investigated. The hydrogen-charged specimens of $200 \mathrm{ppm}$ and $450 \mathrm{ppm}$ were oxidized for $\sim 60$ days at $360^{\circ} \mathrm{C}$ and $17.5 \mathrm{MPa}$ under the water atmosphere. These oxidized hydrogen-charged specimens were found to contain respective hydrogen concentrations of $250 \pm 25 \mathrm{ppm}$ and $500 \pm 25 \mathrm{ppm}$, indicating the further hydrogen pickup during the oxidation process.

During and after the transition, the concentration of hydrogen may strongly depend on the presence of cracks in the oxide layers, formed by the breakaway phenomenon. The cracks within the oxide layer could enhance the oxygen and hydrogen movements through the oxide layer [6]. In such cracks, hydrogen was strongly enriched [47]. At small protective oxide thickness, a fraction of absorbed hydrogen increased with exposure time, then reached a plateau, started to increase again reaching a peak and decreased [48].

There is neither agreed hydrogen diffusion mechanism through the oxide layer nor known data about the hydrogen diffusion coefficient within the oxide [49]. A presence of oxygen may affect hydrogen migration barriers on an atomic scale. Hydrogen can be trapped by oxygen atoms positioned along the preferred path. It means that the trajectory will deviate from a straight line. Secondly, migration barriers for hydrogen between two octahedral interstitials increase when an oxygen atom is present in the neighboring interstitial; migration enthalpy is about $0.6 \mathrm{eV}$ in the absence of oxygen and $0.9 \mathrm{~V}$ in its presence [50].

The oxygen dissolved in the metal considerably decreased the hydrogen absorption capacity of zirconium [19]. The $\mathrm{O}-\mathrm{H}$ bond may appear in the oxide layer, and such trapping can prevent hydrogen diffusion. An oxide layer of $20 \mu \mathrm{m}$ in thickness was formed on the surface of zirconium hydride after hydrogen desorption in the presence of oxygen [9]. A loose zone with holes and cracks appeared on the top of the oxide layer, and a dense and compact layer - on the zirconium hydride. Such oxide layers can change the hydrogen desorption behaviour because they constitute the efficient diffusion barriers on the surface of zirconium hydride.

The nanoscale pores are also introduced by the alloying elements that have a low solid solubility in the $\alpha-\mathrm{Zr}$ matrix and display faster diffusion of their cations in $\mathrm{ZrO}_{2}$ than $\mathrm{Zr}^{4+}$. The oxide porosity provides then short circuits for oxygen and hydrogen diffusion [51].

Aim

So far research has made excellent progress in the recognition of oxidation process, its determinants, the structure of the oxide layers. Similar progress has been observed for hydrogen uptake and diffusion, and an appearance of hydrogen delayed cracking and hydrogen-enhanced creep. However, no such knowledge has been obtained for a role of oxide layers in hydrogen absorption by the metal, which can determine the later hydrogen degradation. Therefore this paper is aimed to determine. 


\section{MATERIAL AND METHODS}

The Zircaloy-2 alloy (Sn 1.36\%, Fe 0.18\%, Cr 0.11\%, Ni 0.07\%, C 0.013\%, Si $0.091 \%$, Al $0.023 \%$, others $<0.01, \mathrm{Zr}$ rem.) delivered by Areva, was investigated. The smooth specimens for slow strain rate tests were cut in the transverse direction to the rolling direction. The specimens had dimensions $120 \mathrm{~mm}$ of total length, $50 \mathrm{~mm}$ of the length of working part and $4 \mathrm{~mm}$ of thickness. The surface preparation was developed based on such far reports, in which different procedures were proposed, from the grinding with the No. 1,200 paper [37] to the paper No. 5,000 and diamond paste $0.5 \mu \mathrm{m}$ [4]. In this research, the specimens were polished with abrasive papers, No. 2,000 as the last, and diamond paste of $3 \mu \mathrm{m}$ of granulation, and then cleaned in distilled water in an ultrasonic bath and dried in warm air.

Afterwards, the specimens were put in the electric oven and heated for $30 \mathrm{~min}$. in laboratory air. The heating temperature was maintained at $350^{\circ} \mathrm{C}, 700^{\circ} \mathrm{C}$ and $900^{\circ} \mathrm{C}$. The first temperature corresponds to the normal working conditions of zirconium pellets; the others approach the conditions of the LOCA nuclear accident. The specimens were put in the oven already heated to the above temperatures and after the oxidation removed and cooled in laboratory air.

Then the specimens were charged with hydrogen. The hydrogenation can be performed by different ways: with gaseous hydrogen at elevated temperature [52-55], with gaseous hydrogen by Sievert's apparatus $[38,56,57]$ or with electrolytic hydrogen at room temperature in $\mathrm{H}_{2} \mathrm{SO}_{4}[16,21,58,59]$ or in $\mathrm{KOH}[17,38,60]$ or at elevated temperature [12]. The cathodic charging with hydrogen at room temperature was chosen as the suitable for simultaneous, in some experiments, slow strain rate tests. The cathodic current density $80 \mathrm{~mA} / \mathrm{cm}^{2}$ was here used as the highest value, by some previous tests [21,58]. The imposed voltage was varied from 2 to $30 \mathrm{~V}$ to try to force the current flow between two electrodes, $\mathrm{Pt}$ and $\mathrm{Zr}$ alloy in oxidised and no oxidised specimens.

The specimens were subjected to slow strain rate test at $10^{-5} \mathrm{~s}^{-1}$ strain rate in $1 \mathrm{M} \mathrm{H}_{2} \mathrm{SO}_{4}$ at ambient temperature. The tests were made with the specially designed and constructed equipment. The force and elongation were monitored during the tensile tests.

In the first series of experiments, the specimens were simultaneously charged and tensed. In the second series, the specimens were oxidized in the same way and afterwards charged with hydrogen without any load at $80 \mathrm{~mA} / \mathrm{cm}^{2}$ for $72 \mathrm{~h}$. Then they removed from the solution, cleaned with distilled water and annealed for $4 \mathrm{~h}$ at $400^{\circ} \mathrm{C}$, following earlier reports $[17,32,56,58,60]$, to obtain the bulk distribution of hydrogen inside the whole specimen. The specimens were put in the oven already heated to the above temperature and after annealing cooled with the oven. The heated specimens were then tensed at the same charging conditions. Both series were made to compare the effects of surface and bulk hydrogen.

The microscopic examinations of the specimens were performed with the JEOL $7800 \mathrm{~F}$ scanning electron microscope on the cross-sections of polished specimens before any test (reference specimens), after oxidation and after hydrogen charging. The etching of crosssections was made with the solution containing $45 \mathrm{~cm}^{3}$ of $65 \% \mathrm{HNO}_{3}, 10 \mathrm{~cm}^{3}$ of $40 \% \mathrm{HF}$ and $45 \mathrm{~cm}^{3}$ of distilled water. After tension, similar examinations were performed on fracture faces to determine the presence and distribution of hydrides, and the mechanism and path of failure. 


\section{RESULTS}

The structure of the alloy before an oxidation is shown in Fig. 1. The significant number of intermetallic $\mathrm{Zr}_{2}(\mathrm{Ni}, \mathrm{Fe})$ and $\mathrm{Zr}(\mathrm{Cr}, \mathrm{Fe})_{2}$ precipitates dispersed in the matrix, is seen.

The surfaces of specimens oxidized at $350^{\circ} \mathrm{C}$ and $700^{\circ} \mathrm{C}$ were smooth and homogenous; only some cracks appeared on surfaces of the last specimens. On the contrary, the surface of specimen oxidized at $900^{\circ} \mathrm{C}$ showed the signs of an early breakaway of likely an upper zone of the oxide layer (the details were discussed in [61]).

The cross-sections of some oxide layers obtained at elevated temperatures are shown in Fig. 3. The increasing oxidation temperature causes an increase in layer thickness, from some nanometers for non-oxidised alloy through about $10 \mu \mathrm{m}$ after the oxidation at $700^{\circ} \mathrm{C}$ to about $25 \mu \mathrm{m}$ after the oxidation at $900^{\circ} \mathrm{C}$ for $0.5 \mathrm{~h}$.

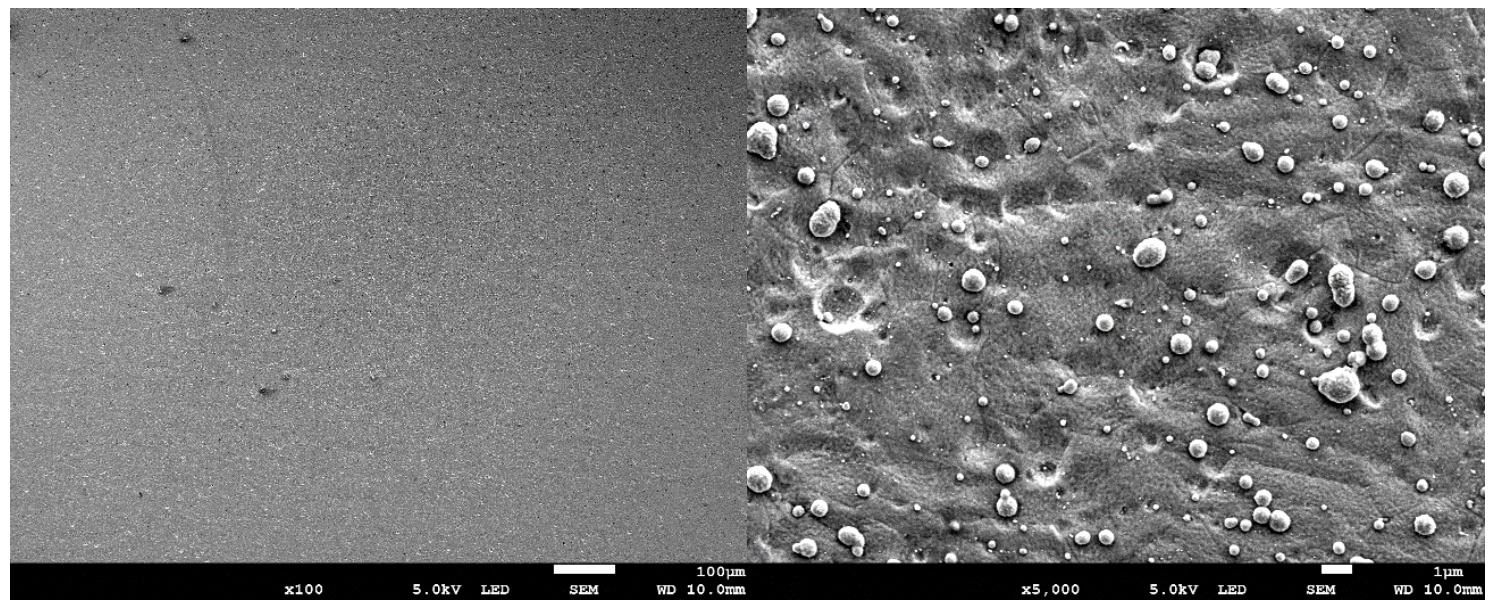

Fig. 1. The cross-sections of the as-received Zircaloy-2 alloy (different magnification)

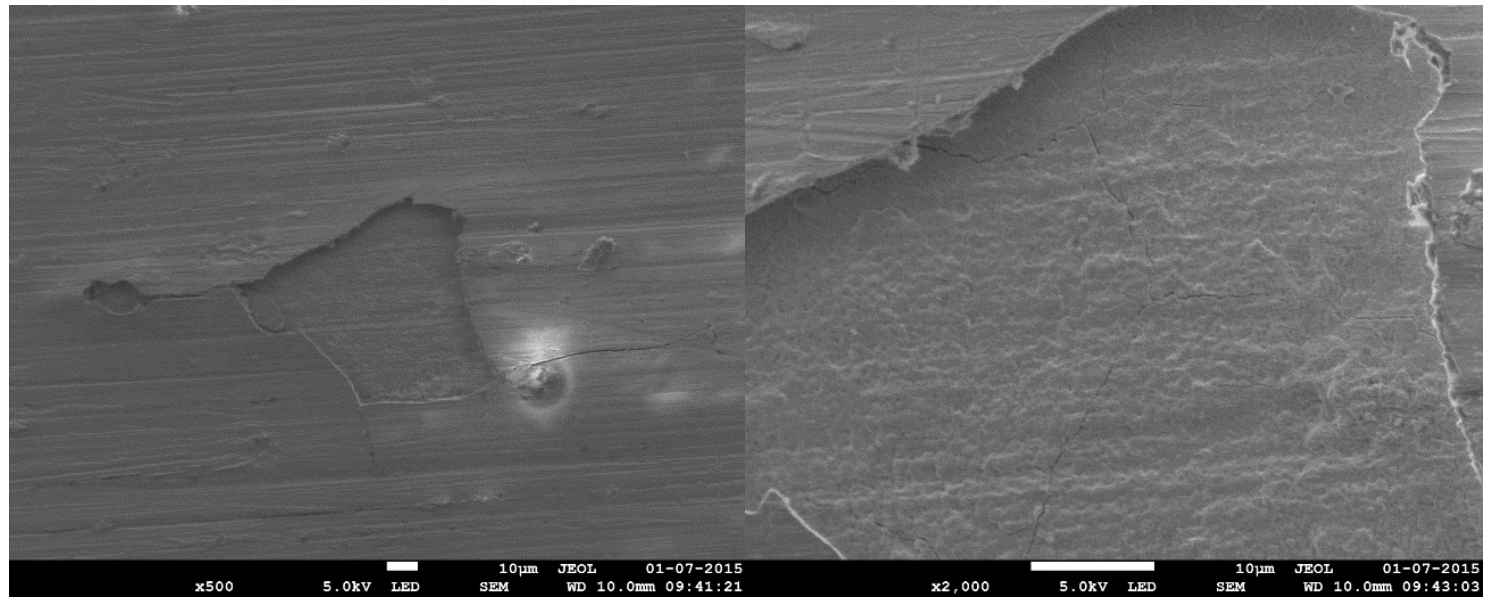

Fig. 2. View of surfaces of the specimen oxidized at $900^{\circ} \mathrm{C}$ for $0.5 \mathrm{~h}$ 


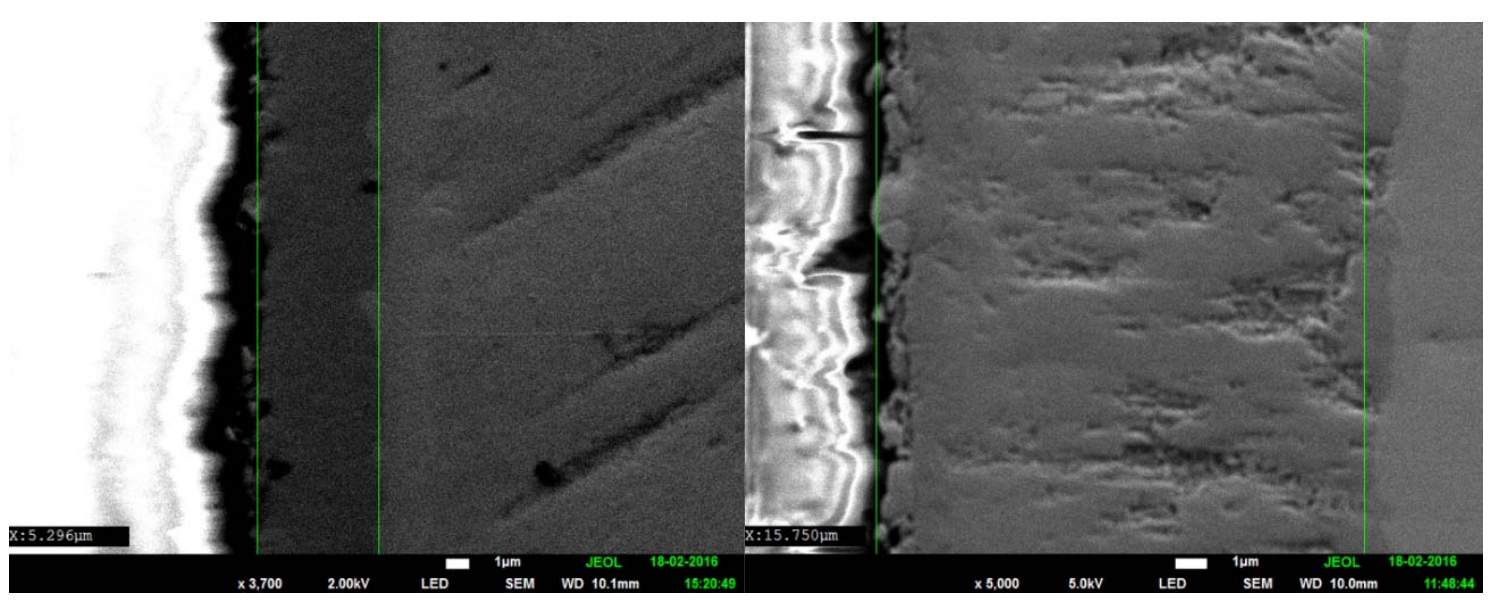

Fig. 3. Cross-sections of the oxide layers a) after oxidation at $700^{\circ} \mathrm{C}$ for $0.5 \mathrm{~h}, \mathrm{~b}$ ) after oxidation at $900^{\circ} \mathrm{C}$ for 0.5 h. The green lines show the oxide thickness

The stress - strain curves are demonstrated in Fig. 4 for both non-oxidized (reference) and oxidized and hydrogen charged in different conditions specimens. The hydrogen charging has a small and complex effect on tensile properties. The specimens tensed and charged simultaneously demonstrate the highest tensile strength and those charged, annealed and tensed - a little smaller tensile strength and similar elongation. The no-charged specimens have the comparable tensile strength and the smallest elongation. The oxidation at $900^{\circ} \mathrm{C}$ causes an apparent decrease in plasticity.

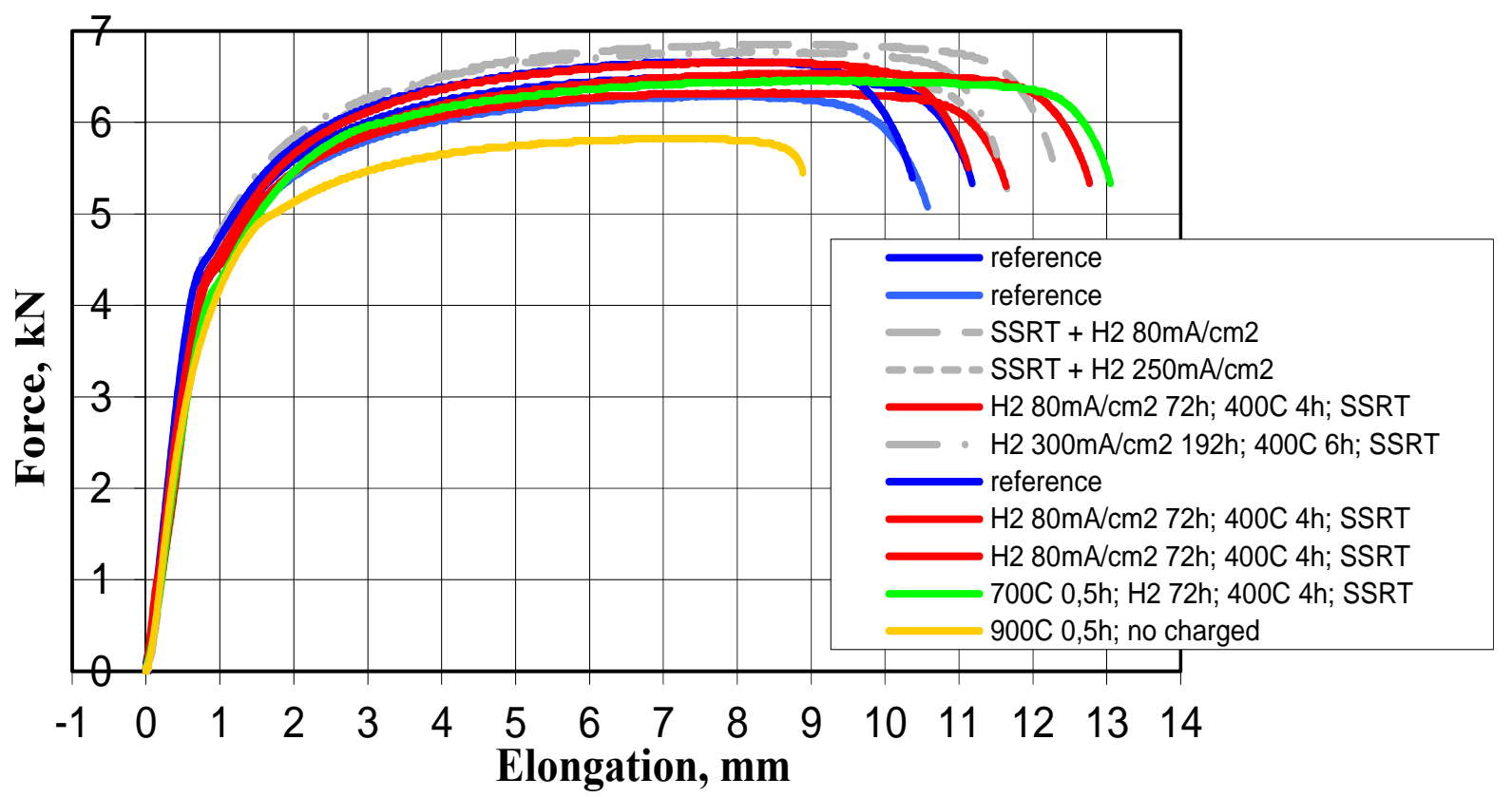

Fig. 4. Stress - strain curves for specimens oxidized at $350^{\circ} \mathrm{C}$, and charged with hydrogen during SSRT or charged, annealed and tensed, and for reference specimens. The cathodic current density, charging time, temperature and time of annealing, are shown 
The cross-sections of some oxidized at $350^{\circ} \mathrm{C}$ and hydrogen charged specimens are shown in Fig. 5 for the specimens simultaneously charged and tensed, and the specimens charged, heated at $400^{\circ} \mathrm{C}$ and then tensed. The first specimens demonstrate the microstructure similar to no-charged specimens, even close to the oxide - matrix boundary (not shown here). On the contrary, on specimens tensed after hydrogen charging and annealing the lines of cracks caused by the hydrides are long about $100 \mu \mathrm{m}$ and randomly distributed in the matrix, and branched.

a)

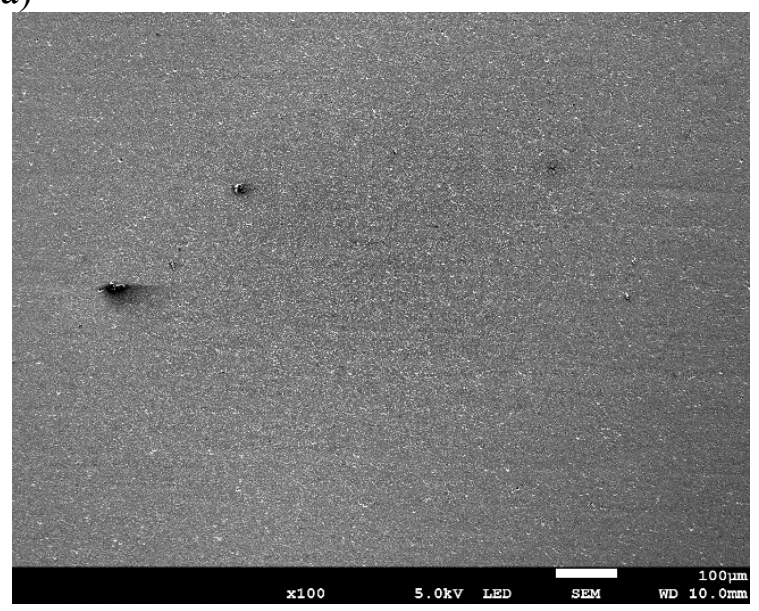

c)

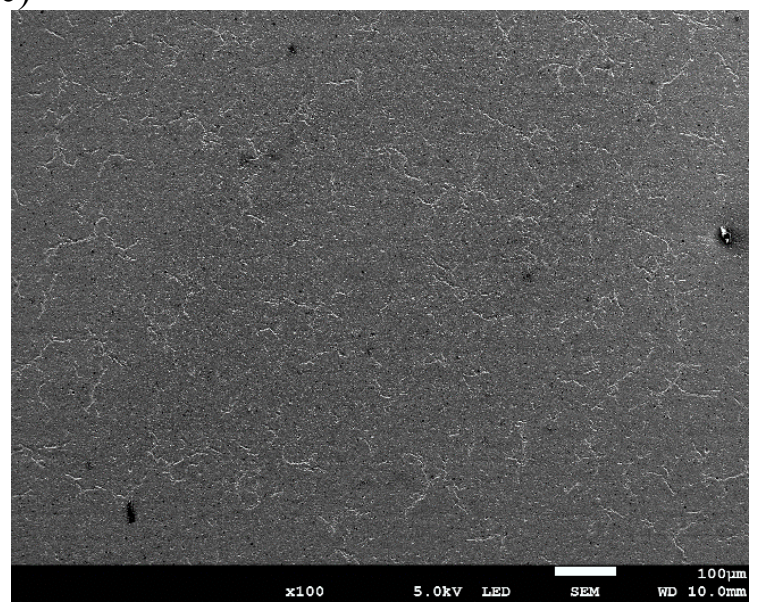

b)

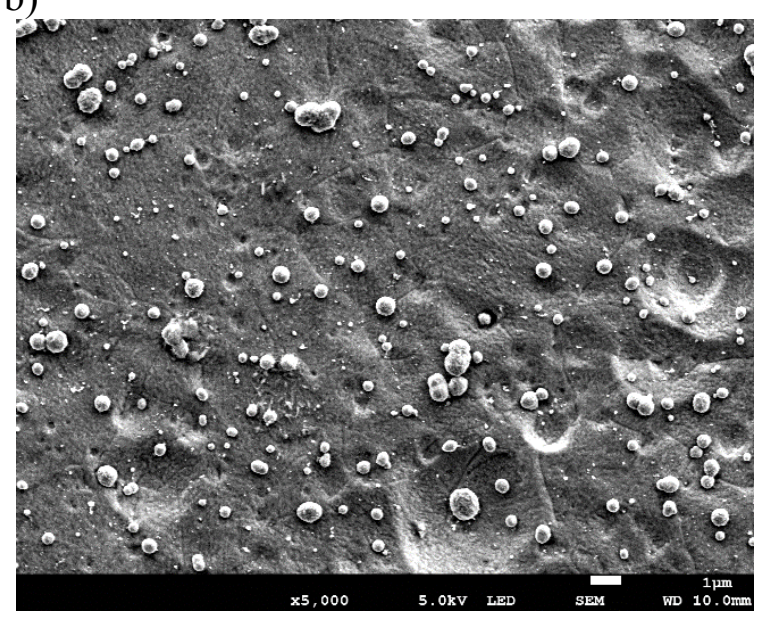

d)

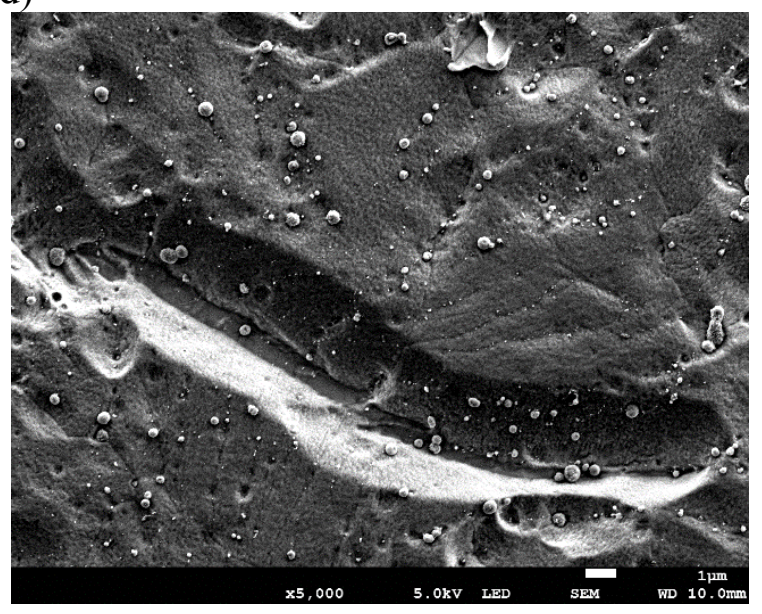

Fig. 5. The cross-sections of specimens oxidized at $350^{\circ} \mathrm{C}$ and: $\left.\mathrm{a}, \mathrm{b}\right)$ simultaneously hydrogen charged at 80 $\mathrm{mA} / \mathrm{cm}^{2}$ and tensed; c, d) hydrogen charged at $80 \mathrm{~mA} / \mathrm{cm}^{2}$ for $72 \mathrm{~h}$, heated at $400^{\circ} \mathrm{C}$ for $4 \mathrm{~h}$ and then tensed

The cross-sections of the alloy oxidized at $700^{\circ} \mathrm{C}$ and hydrogen charged specimens are shown in Fig. 6 for the specimens simultaneously charged and tensed and the specimens charged, heated at $400^{\circ} \mathrm{C}$ and then tensed. Some small cracks, up to a few micrometers in length, are visible at higher magnifications. 
a)

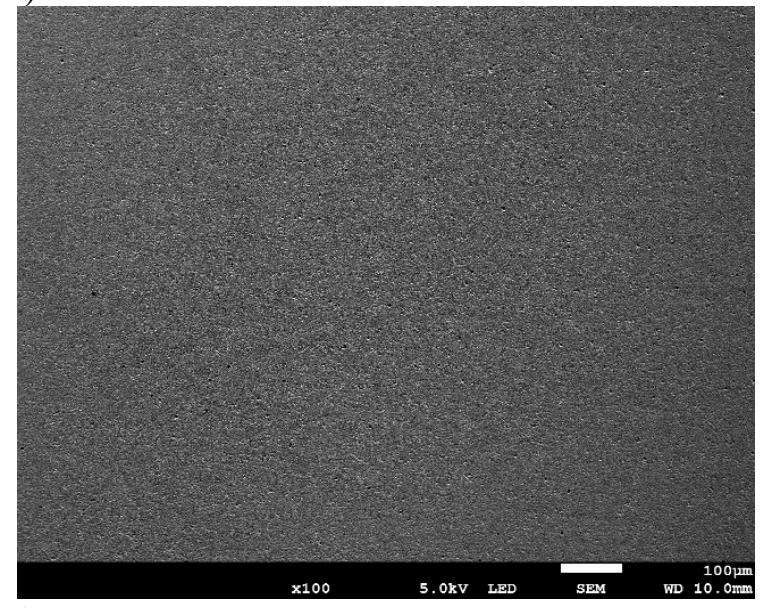

c)

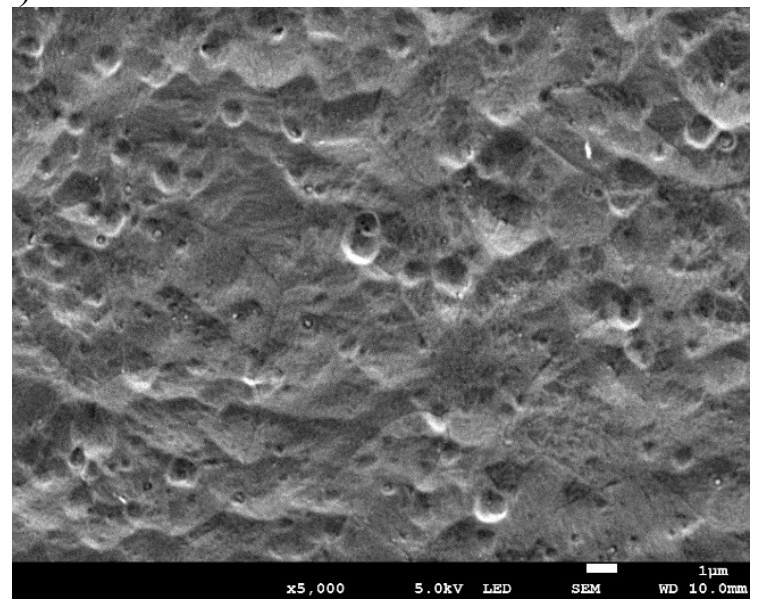

b)

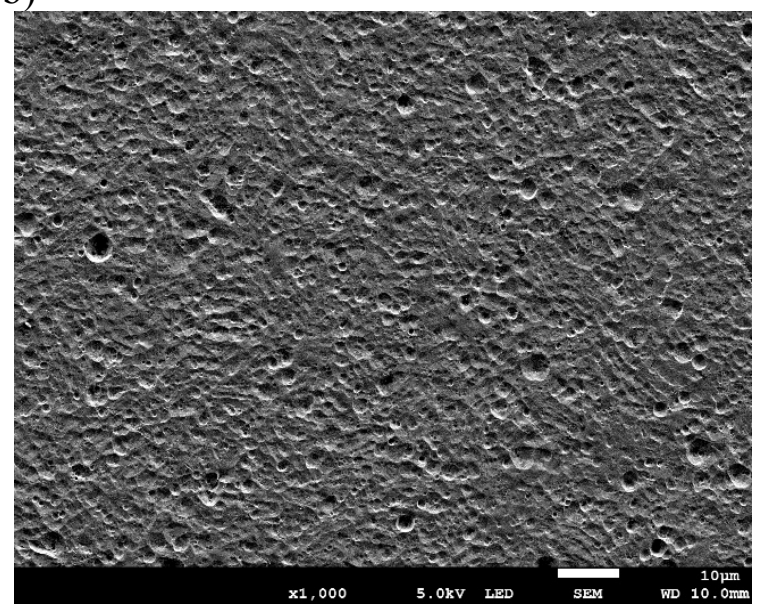

d)

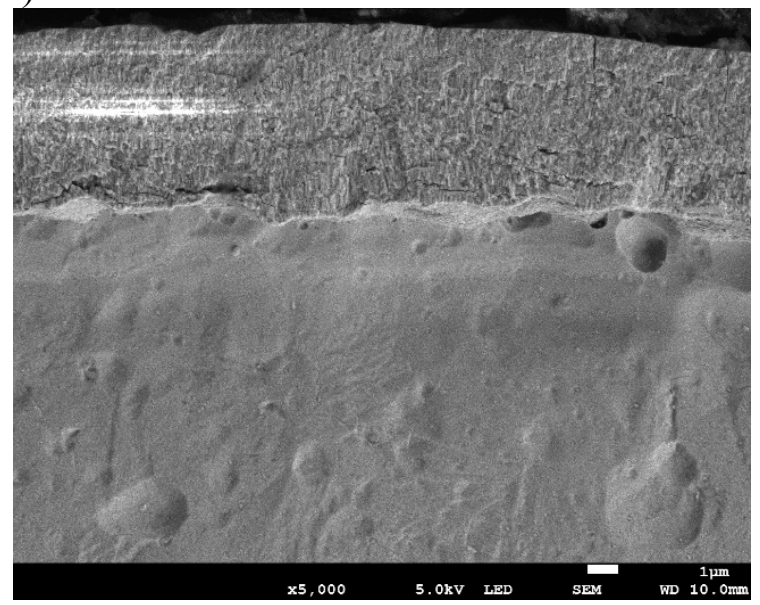

Fig. 6. The cross-sections of specimens oxidized at $700^{\circ} \mathrm{C}$, hydrogen charged at $80 \mathrm{~mA} / \mathrm{cm}^{2}$ for $72 \mathrm{~h}$, heated at $400^{\circ} \mathrm{C}$ for $4 \mathrm{~h}$ and then tensed, at different magnifications and different area of the specimen

The fracture faces after oxidation at $350^{\circ} \mathrm{C}$ and hydrogen charging are shown in Fig. 7 for the specimens simultaneously charged and tensed, and the specimens hydrogen charged, annealed at $400^{\circ} \mathrm{C}$ and then tensed. The ductile transgranular fracture is observed for the first specimens and similar fracture with likely both intergranular and transgranular cracks for the second group of specimens.

a)

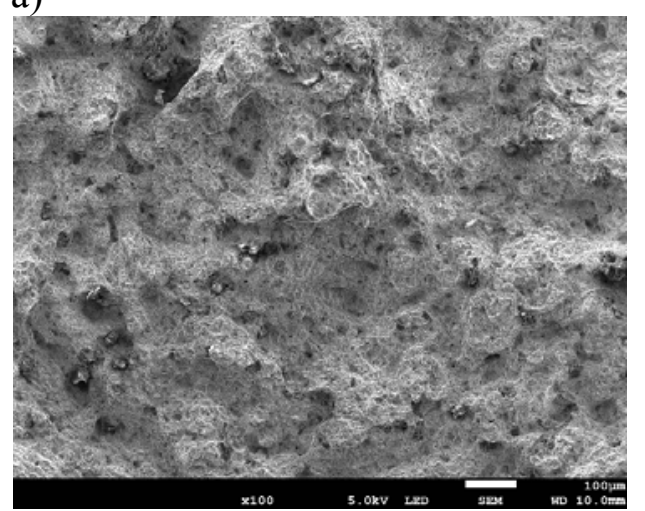

c) b)

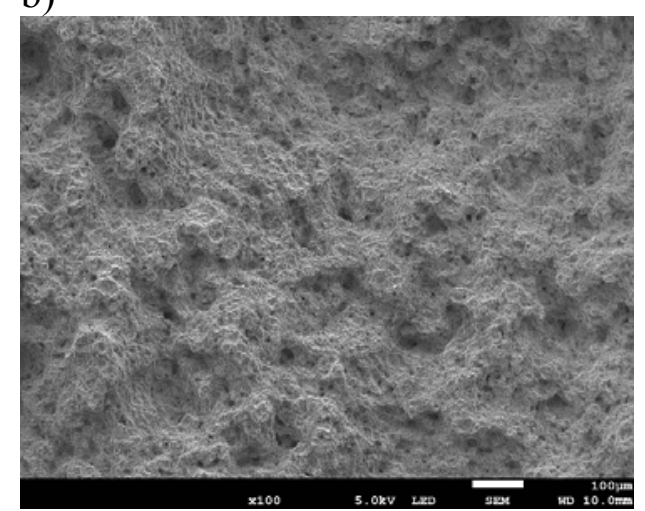

d) 

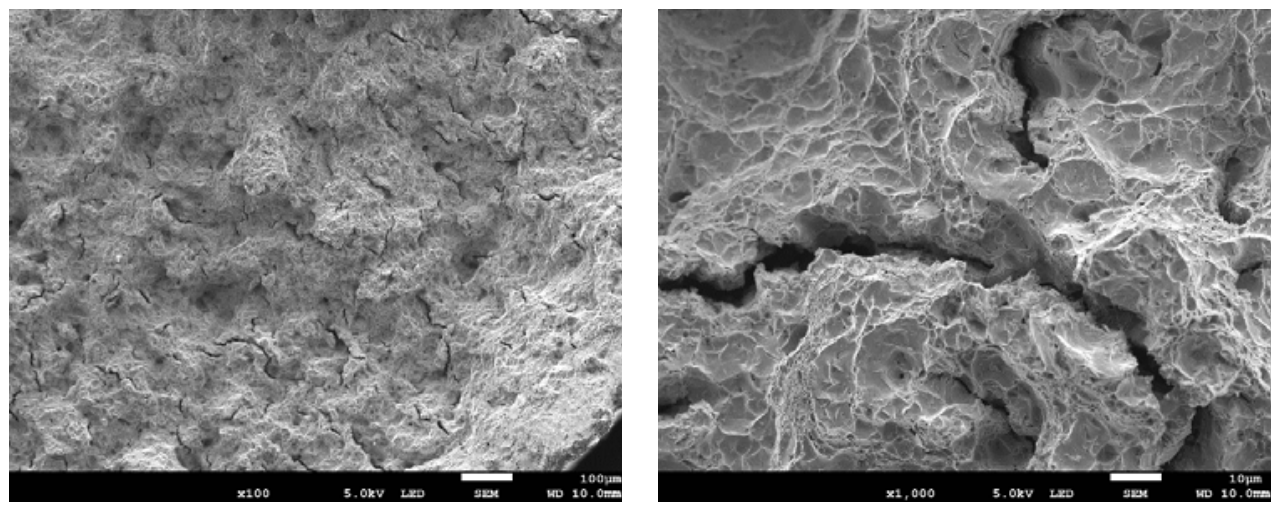

Fig. 7. The fracture faces of the specimens oxidized at $350^{\circ} \mathrm{C}$ and: a, b) simultaneously hydrogen charged at $80 \mathrm{~mA} / \mathrm{cm}^{2}$ and tensed; c, d) hydrogen charged at $80 \mathrm{~mA} / \mathrm{cm}^{2}$ for $72 \mathrm{~h}$, heated at $400^{\circ} \mathrm{C}$ for $4 \mathrm{~h}$ and then tensed

The fracture faces after oxidation at $700^{\circ} \mathrm{C}$ and hydrogen charging are shown in Fig. 8 for the hydrogen charged specimen, annealed at $400^{\circ} \mathrm{C}$ and then tensed. The ductile transgranular fracture is always observed with very short cracks.

a)

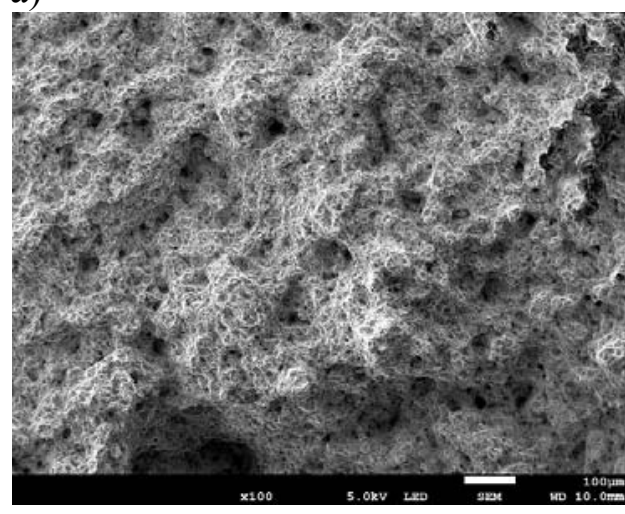

b)

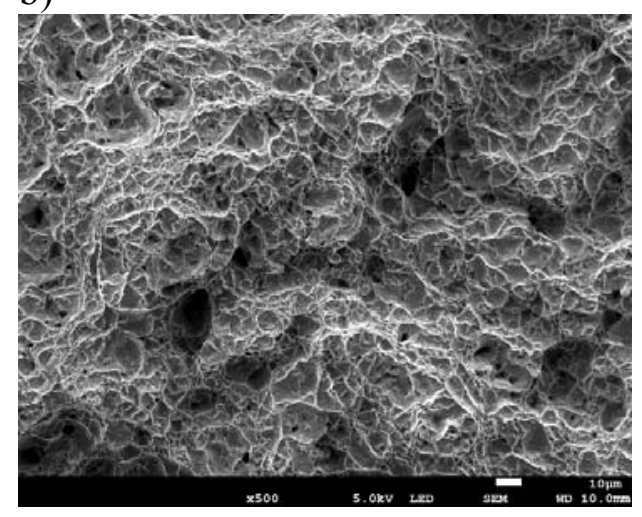

Fig. 8. The fracture faces of the specimens oxidized at $700^{\circ} \mathrm{C}$, hydrogen charged at $80 \mathrm{~mA} / \mathrm{cm}^{2}$ for $72 \mathrm{~h}$, heated at $400^{\circ} \mathrm{C}$ for $4 \mathrm{~h}$ and then tensed

Table 1 demonstrates the effect of oxidation time on cathodic charging parameters under constant voltage conditions. The increase in oxidation temperature from $350^{\circ} \mathrm{C}$ to $700^{\circ} \mathrm{C}$ results in a drastic decrease in cathodic current, and from $350^{\circ} \mathrm{C}$ to $900^{\circ} \mathrm{C}-$ in fall of the current to zero.

Table 1. Cathodic charging parameters

\begin{tabular}{|l|c|c|c|}
\hline Oxidation temperature & $\begin{array}{c}\text { Cathodic current } \\
\text { density }\end{array}$ & Cathodic voltage & Charging time \\
\hline $350^{\circ} \mathrm{C} / 30 \mathrm{~min}$. & $80 \mathrm{~mA} / \mathrm{cm} 2$ & $3 \mathrm{~V}$ to $2 \mathrm{~V}$ & $72 \mathrm{~h}$ \\
\hline $700^{\circ} \mathrm{C} / 30 \mathrm{~min}$. & $20-40 \mathrm{~mA} / \mathrm{cm} 2$ & $10 \mathrm{~V}$ & $72 \mathrm{~h}$ \\
\hline $900^{\circ} \mathrm{C} / 30 \mathrm{~min}$. & 0 & $30 \mathrm{~V}$ & $72 \mathrm{~h}$ \\
\hline
\end{tabular}

The mean hydrogen content, for the specimens oxidized at $350^{\circ} \mathrm{C}$, hydrogen charged at $80 \mathrm{~mA} / \mathrm{cm}^{2}$ for $72 \mathrm{~h}$, annealed at $400^{\circ} \mathrm{C}$ for $6 \mathrm{~h}$ and then tensed, equals $73.9 \pm 14.1 \mathrm{wt}$. ppm. For specimens oxidized at higher temperatures, the hydrogen content is about $15 \mathrm{ppm}$, within the limits of experimental error. 
One might assume that at the thin oxide layer hydrogen can enter the metal and at imposed high current/voltage parameters the hydrides can form at the oxide/metal interface. It is to note that the hydrogen amount was in each test sufficient to form hydrides. However, we did not observe any hydrides in nonannealed specimens; they likely appeared in a very thin zone close to the interface because of a low hydrogen diffusion coefficient, $\mathrm{H}_{\mathrm{D}}$, about $10^{-7}$ to $10^{-10} \mathrm{~cm}^{2} / \mathrm{s}$, according to various researchers [62].

During our standard charging time $72 \mathrm{~h}$, hydrogen can diffuse for distance:

$$
\mathrm{x}=(\mathrm{D} \mathrm{t})^{1 / 2}
$$

For $D_{H}=10^{-7} \mathrm{~cm}^{2} / \mathrm{s}$, the distance is about $1610 \mu \mathrm{m}$, and for $D_{H}=10^{-10} \mathrm{~cm}^{2} / \mathrm{s}$, it is 50.9 $\mu \mathrm{m}$. As we have not observed any hydrides near the oxide - matrix interface at high magnification on the cross - sections, the hydrogen diffusion coefficient seems close rather to the second value or even be lower. Both values have been calculated from an extrapolation of high-temperature data, and it is possible that the hydrogen coefficient value at low temperatures deviates from that predicted by the Arrhenius law because of hydrogen trapping.

During annealing at $400^{\circ} \mathrm{C}$, the approximate values of $\mathrm{D}_{\mathrm{H}}$ can be as reported between $10^{-5}$ to $10^{-8} \mathrm{~cm}^{2} / \mathrm{s}$. Based on the above Fick equation, the distances of hydrogen migration are between $0.509 \mathrm{~mm}$ and $1.61 \mathrm{~cm}$. The microscopic examinations show, however, that the distribution of hydrides is regular and on the whole surface so that the applied annealing conditions have been adequate and the hydrogen diffusion coefficient is closer rather to the higher of above values.

The effects of hydrogen on stress-strain curves in such conditions are of minor importance. The only distinct loss of elongation after oxidation at $900^{\circ} \mathrm{C}$ is likely originated from grain recrystallization at this high temperature as no hydrogen can enter the specimen at zero current value. The hydrogen absorption seems to result in moderate softening, likely by interstitial hydrogen. The results are by some earlier reports [27,28]. The effects of interstitial hydrogen and hydride phases are opposite, but the distinct loss of plasticity observed in another studies $[25,26,29,31]$ might appear at high hydrogen content and a great number of hydrides. The separation of these effects is not easy at low hydrogen content.

The slow strain rate tests have been never made for simultaneously tensed and hydrogen charged $\mathrm{Zr}$ alloys. For many metallic materials, the slow strain rate tests in the corrosive or hydrogen-containing environment have shown the initiation of cracks on the surface and their significant progress during tensile tests. Such behaviour has been considered as due to the hydrogen screening of dislocations, a decrease of their mutual interaction and movement of dislocations at lower flow stress, i.e. local softening of material at macroscopically brittle fracture known as the Hydrogen Enhanced Localised Plasticity (HELP). The lack of such effect for specimens nonoxidized and oxidized at $350^{\circ} \mathrm{C}$ is evidence that this mechanism may be unable to cause the movement and multiplication of dislocations. Thus the propagation of cracks even at low hydrogen content may occur via Hydrogen Enhanced Decohesion as sometimes suggested in the past [35], likely because of very low interstitial hydrogen content at low temperature. At high temperatures, on the other hand, the dislocations cannot be pinned by hydrogen atoms.

When, at the same conditions, the annealing has been performed after charging, we have observed the appearance of branched hydrides. However, the cracking mechanism changed only a little: the metal fractured by ductile mechanism and in a transgranular way. The cleavage or quasi-cleavage fracture could be observed only at the hydride - matrix interface. 
The effect of the oxide layer is the most important finding. The presence of $10 \mu \mathrm{m}$ oxide layer after the oxidation at $700^{\circ} \mathrm{C}$ causes the apparent decrease in current value. Such oxide layer is still stable and shows neither the breakaway effect nor a presence of cracks penetrating through the oxides. One might say that the oxide layer is permeable to hydrogen atoms, but the hydrogen diffusion at room temperature through this layer is very low.

The effect of oxidation at $900^{\circ} \mathrm{C}$ is surprising. Even after annealing at $400^{\circ} \mathrm{C}$ for $6 \mathrm{~h}$, the zero current is observed, then the hydrogen atoms are unable to cross over the $25 \mu \mathrm{m}$ oxide layer during $72 \mathrm{~h}$ of charging. A comparison of both effects makes it possible to assess the diffusion rate of hydrogen within the oxide layer from the equation (1):

$$
\begin{gathered}
\left(10 \times 10^{-4}\right)^{2} / 2.59 \times 10^{-5}<\mathrm{D}_{\mathrm{H} / \mathrm{ox}}<\left(25 \times 10^{-4}\right)^{2} / 2.59 \times 10^{-5} \\
3.86 \times 10^{-12} \mathrm{~cm}^{2} / \mathrm{s}<\mathrm{D}_{\mathrm{H} / \mathrm{ox}}<2.41 \times 10^{-11} \mathrm{~cm}^{2} / \mathrm{s}
\end{gathered}
$$

So far there has been known no data on the hydrogen diffusion coefficient in the zirconium oxide, and this result is the first. Even if it is indirect value, it is very reasonable and explains why the presence of continuous oxide layer may be very important for prevention of hydrogen entry into the zirconium pellets.

It is symptomatic that the above effects are observed even at substantial breakaway of the zirconia layer after oxidation at $900^{\circ} \mathrm{C}$. The breakaway is limited only to the outer oxide layer, with the inner oxide layer still compact and well adjacent to the base. In earlier research, no such positive effect of pre-oxidation has been observed [46]. Despite that, based on present results we assume that the pre-oxidation may to some extent prevent the hydrogen entry and degradation during the LOCA nuclear accident. Our next tests will be performed to assess how the oxidation temperature and time may affect the barrier effect on zirconium alloys.

The most important safety condition for nuclear power plants is the reliability of nuclear reactors. The maintenance properties may then depend, among others, on thickness, continuity (lack of cracks), adhesion and morphology of the oxide layer, determining the resistance to hydrogen degradation of fuel claddings. The present research may indicate, after further detailed verification with other parameters, alloys, and environments, the surface modification method of zirconium fuel pellets as improving their behaviour in conditions of the LOCA nuclear accident.

\section{CONCLUSIONS}

Hydrogen, in an amount below 100 wt. ppm has a moderate effect on stress-strain curves. The hydrogen absorption seems to result in moderate softening, likely by interstitial hydrogen. The appearance of hydrides results in branched cracks initiating at and propagating from hydride - matrix interfaces.

The presence of $10 \mu \mathrm{m}$ oxide layer after the oxidation at $700^{\circ} \mathrm{C}$ causes the apparent decrease in current value and hydrogen entry, and after the oxidation at $900^{\circ} \mathrm{C}$ results in no hydrogen absorption even in the presence of the breakaway phenomenon. The oxide layer is permeable to hydrogen atoms, but the hydrogen diffusion at room temperature through this layer seems very low.

The measurements of cathodic current at different thickness of oxide layer gives a possibility to calculate the hydrogen diffusion coefficient $\mathrm{D}_{\mathrm{H} / \mathrm{ox}}$ within the oxide layer. Based on that, the $\mathrm{D}_{\mathrm{H} / \mathrm{ox}}$ is estimated as being between $3.86 \times 10^{-12} \mathrm{~cm}^{2} / \mathrm{s}$ and $2.41 \times 10^{-11} \mathrm{~cm}^{2} / \mathrm{s}$. 
The present results suggest that pre-oxidation may to some extent prevent the hydrogen entry and degradation during the LOCA nuclear accident. The verification of this assumption should be made in particular for higher test temperature and vapor environment.

\section{ACKNOWLEDGMENTS}

This work was supported by the National Science Centre, Poland [grant No. 2013/11/B/ST8/04328].

\section{REFERENCES}

1. Steinbrück M., Böttcher M., Air oxidation of Zircaloy-4, M5 and ZIRLOTM cladding alloys at high temperatures. J Nucl Mater 2011; 414:276-85.

2. Zielinski A., Sobieszczyk S., Hydrogen-enhanced degradation and oxide effects in zirconium alloys for nuclear applications. Intl J Hydrogen Energy 2011;36:8619-29.

3. Lelièvre G., Fruchart D., Convert P., Lefè vre-Joud F., Characterisation by neutron diffraction in high temperature pressurized water of the surface corrosion and hydrogen embrittlement of zircaloy-4. J Alloys Comp 2002;347:288-94.

4. Zeng C., Ling Y., Bai Y., Zhang R., Dai X., Chen Y., Hydrogen permeation characteristic of nanoscale passive films formed on different zirconium alloys. Intl J Hydrogen Energy 2016; 41:7676-90.

5. Selmi N., Sari A., Study of Oxidation Kinetics in Air of Zircaloy-4 by in Situ X-Ray Diffraction. Adv Mater Phys Chem 2013;3:168-73.

6. Baek J. H., Jeong Y. H., Breakaway phenomenon of Zr-based alloys during a high-temperature oxidation. J Nucl Mater 2008;372:152-9.

7. Allen T. R., Konings R. J. M., Motta A. T., Corrosion of Zirconium Alloys. In: Konings RJM, editor. Comprehensive Nuclear Materials, Amsterdam: Elsevier: 2012, vol. 5, p. 49-68.

8. Gabory de B., Motta A. T., Wang K., Transmission electron microscopy characterization of Zircaloy-4 and ZIRLO ${ }^{\mathrm{TM}}$ oxide layers. J Nucl Mater 2015;456:272-80.

9. Chen W., Wang L., Lu S., Influence of oxide layer on hydrogen desorption from zirconium hydride. J Alloys Comp 2009;469:142-5.

10. Birchley J., Fernandez-Moguel L., Simulation of air oxidation during a reactor accident sequence: Part 1 - Phenomenology and model development. Ann Nucl Energy 2012;40:163-70.

11. Hózer Z., Győri C., Matus L., Horvàth M., Ductile-to-brittle transition of oxidised Zircaloy-4 and E110 claddings. J Nucl Mater 2008;373:415-23.

12. Elmoselhi M. B., Hydrogen uptake by oxidized zirconium alloys. J Alloys Comp 1995;231:71621.

13. Steinbrück M., Birchley J., Boldyrev A. V., Goryachev A. V., Grosse M., Haste T. J., et al., Hightemperature oxidation and quench behaviour of Zircaloy-4 and E1 10 cladding alloys. Progr Nucl Energy 2010;52:19-36. 
14. Fernandez-Moguel L., Birchley J., Simulation of air oxidation during a reactor accident sequence: Part 2 - Analysis of PARAMETER-SF4 air ingress experiment using RELAP5/SCDAPSIM. Ann Nucl Energy 2012;40:141-52.

15. Coindreau O., Duriez Ch., Ederli S., Air oxidation of Zircaloy-4 in the 600-1000 C temperature range: modelling for ASTEC Code application. J Nucl Mater 2010;405:207-51.

16. Kim J. H., Lee M. H., Choi B. K., Jeong Y. H., Effects of oxide and hydrogen on the circumferential mechanical properties of Zircaloy-4 cladding. Nucl Eng Design 2006;236:186773.

17. Bertolino G., Meyer G., Perez Ipiña J., Degradation of the mechanical properties of Zircaloy-4 due to hydrogen embrittlement. J Alloys Comp 2002;330-332:408-13.

18. Zielinski A., Degradation of some hydride-forming metals and their alloys. In: Goltsov VA. Editor. Progress in Hydrogen Treatment of Materials, Donetsk, Ukraina \& Coral Gables, USA: Internal Association for Hydrogen Energy; 2001, 451-472.

19. Steinbrück M., Hydrogen absorption by zirconium alloys at high temperatures. J Nucl Mater 2004;334:58-64.

20. Shrivastava K. S., Kulkarni A. S., Ramanjaneyulu P. S., Sunil S., Saxena M. K., Singh R. N., et al., Determination of diffusion coefficients of hydrogen and deuterium in $\mathrm{Zr}-2.5 \% \mathrm{Nb}$ pressure tube material using hot vacuum extraction-quadrupole mass spectrometry. J Nucl Mater 2015;461:151-6.

21. Liu Y., Peng Q., Zhao W., Jiang H., Hydride precipitation by cathodic hydrogen charging method in zirconium alloys. Mater Chem Phys 2008;110:56-60.

22. Lanzani L., Ruch M., Comments on the stability of zirconium hydride phases in Zircaloy. J Nucl Mater 2004;324:165-76.

23. Daum R. S., Chu Y. S., Motta A. T., Identification and quantification of hydride phases in Zircaloy-4 cladding using synchrotron X-ray diffraction. J Nucl Mater 2009;392:453-63.

24. Qin W., Szpunar J. A., Kozinski J., Hydride-induced degradation of hoop ductility in textured zirconium-alloy tubes: A theoretical analysis. Acta Mater 2012;60:4845-55.

25. Blackmur M. S., Robson J. D., Preuss M., Zanellato O., Cernik R. J., Shi S-O., et al., Zirconium hydride precipitation kinetics in Zircaloy-4 observed with synchrotron X-ray diffraction. J Nucl Mater 2015;464:160-9.

26. Le Saux M., Besson J., Carassou S., Poussard C., Averty X., Behavior and failure of uniformly hydrided Zircaloy-4 fuel claddings between $25^{\circ} \mathrm{C}$ and $480^{\circ} \mathrm{C}$ under various stress states, including RIA loading conditions. Eng Failure Analys 2010;17:683-700.

27. Oh S., Jang C., Kim J. H., Jeong Y. H., Effect of $\mathrm{Nb}$ on hydride embrittlement of $\mathrm{Zr}-\mathrm{xNb}$ alloys. Mater Sci Eng A 2010;527:1306-13.

28. Yamanaka S., Setoyama D., Muta H., Uno M., Kuroda M., Takeda K., et al., Characteristics of zirconium hydrogen solid solution. J Alloys Comp 2004;372:129-35

29. Hong S. I., Lee K. W., Kim K. T., Effect of the circumferential hydrides on the deformation and fracture of Zircaloy cladding tubes. J Nucl Mater 2002;303:169-76.

30. Pierron O. N., Koss D. A., Motta A. T., Chan K. S., The influence of hydride blisters on the fracture of Zircaloy-4. J Nucl Mater 2003;322:21-35.

31. Kim J. H., Lee M. H., Choi B. K., Jeong Y. H., Effect of the hydrogen contents on the circumferential mechanical properties of zirconium alloy claddings. J Alloys Comp 2007;431:155-61. 
32. Lee K. W., Hong S. I., Zirconium hydrides and their effect on the circumferential mechanical properties of $\mathrm{Zr}-\mathrm{Sn}-\mathrm{Fe}-\mathrm{Nb}$ tubes. J Alloys Comp 2002;346:302-7.

33. Min S-J., Kim M-S., Kim K-T., Cooling rate- and hydrogen content-dependent hydride reorientation and mechanical property degradation of $\mathrm{Zr}-\mathrm{Nb}$ alloy claddings. J Nucl Mater 2013;441:306-14.

34. Daunys M., Dundulis R., Grybenas A., Krasauskas P., Hydrogen influence on mechanical and fracture mechanics characteristics of zirconium $\mathrm{Zr}-2.5 \mathrm{Nb}$ alloy at ambient and elevated temperatures. Nucl Eng Design 2008;238:2536-45.

35. Chakraborty P., Moitra A., Saha-Dasgupta T., Effect of hydrogen on degradation mechanism of zirconium: A molecular dynamics study. J Nucl Mater 2015;466:172-8.

36. Huang J-H., Yeh M-S., Gaseous Hydrogen Embrittlement of a Hydrided Zirconium Alloy. Met Mater Trans A 1998;29:1047-56.

37. Zhao C., Song X., Yang Y., Zhang B., Hydrogen absorption cracking of zirconium alloy in the application of nuclear industry. Intl J Hydrogen Energy 2013;38:10903-11.

38. Bertolino G., Meyer G., Perez Ipiña J., Effects of hydrogen content and temperature on fracture toughness of Zircaloy-4. J Nucl Mater 2003;320:272-9.

39. Pshenichnikov A., Stuckert J., Walter M., Hydride precipitation, fracture and plasticity mechanisms in pure zirconium and Zircaloy-4 at temperatures typical for the postulated loss-ofcoolant accident. Nucl Eng Design 2016;301:366-77.

40. Udagawa Y., Yamaguchi M., Abe H., Sekimura N., Fuketa T., Ab initio study on plane defects in zirconium-hydrogen solid solution and zirconium hydride. Acta Mater 2010;58:3927-38.

41. McRae G. A., Coleman C. E., Leitch B. W., The first step for delayed hydride cracking in zirconium alloys. J Nucl Mater 2010;396:130-43.

42. Yamanaka S., Nishizaki T., Uno M., Katsura M., Hydrogen dissolution into zirconium oxide. J Alloys Comp 1999;293-295:38-41.

43. Grosse M., Steinbrueck M., Lehmann E., Vontobel P., Kinetics of Hydrogen Absorption and Release in Zirconium Alloys During Steam Oxidation. Oxid Met 2008;70:149-162.

44. Kiran Kumar M., Aggarwal S., Kain V., Saario T., Bojinov M., Effect of dissolved oxygen on oxidation and hydrogen pick up behaviour-Zircaloy vs $\mathrm{Zr}-\mathrm{Nb}$ alloys. Nucl Eng Design 2010;240:985-94.

45. Sundell G., Thuvander M., Andrén H-O., Barrier oxide chemistry and hydrogen pick-up mechanisms in zirconium alloys. Corr Sci 2016;102:490-502.

46. Cha H-J., Jang K-N., An J-H., Kim K-T., The effect of hydrogen and oxygen contents on hydride reorientations of zirconium alloy cladding tubes. Nucl Eng Techn 2015;147:746-55.

47. Große M., Lehmann E., Steinbrück M., Kühne G., Stuckert J., Influence of oxide layer morphology on hydrogen concentration in tin and niobium containing zirconium alloys after high temperature steam oxidation. J Nucl Mater 2009;385:339-45.

48. Couet A., Motta A. T., Comstock R. J., Hydrogen pickup measurements in zirconium alloys: Relation to oxidation kinetics. J Nucl Mater 2014;451:1-13.

49. Suman S., Khan M. K., Pathak M., Singh R. N., Chakravartty J. K., Hydrogen in Zircaloy: Mechanism and its impacts. Intl J Hydrogen Energy 2015;49:5976-94.

50. Glazoff M. V., Tokuhiro A., Rashkeev S. N., Sabharwall P., Oxidation and hydrogen uptake in zirconium, Zircaloy-2 and Zircaloy-4: Computational thermodynamics and ab initio calculations. J Nucl Mater 2014;444:65-75. 
51. Gong W., Zhang H., Wu C., Tian H., Wang X., The role of alloying elements in the initiation of nanoscale porosity in oxide films formed on zirconium alloys. Corr Sci 2013;77:391-6.

52. Neogy S., Srivastava D., Tewari R., Singh R. N., Dey G. K., Banerjee S., Microstructural study of hydride formation in Zr-1Nb alloy. J Nucl Mater 2003;322:195-203.

53. Hsu H-H., An evaluation of hydrided Zircaloy-4 cladding fracture behavior by X-specimen test. J Alloys Comp 2006;426:256-62.

54. Singh R. N., Kumar N., Kishore R., Roychaudhury S., Sinha T. K., Kashyap B. P., Delayed hydride cracking in $\mathrm{Zr}-2.5 \mathrm{Nb}$ pressure tube material. J Nucl Mater 2002;304:189-203.

55. Mani Krishna K. V., Sain A., Samajdar I., Dey G. K., Srivastava D., Neogy S., et al., Resistance to hydride formation in zirconium: An emerging possibility. Acta Mater 2006;54:4665-75.

56. Bind A. K., Singh R. N., Khandelwal H. K., Sunil S., Avinash G., Chakravartty J. K., et al., Influence of loading rate and hydrogen content on fracture toughness of $\mathrm{Zr}-2.5 \mathrm{Nb}$ pressure tube material. J Nucl Mater 2015;465:177-88.

57. Viswanathan U. K., Singh R. N., Basak C. B., Anantharaman S., Sahoo K. C., Evaluation of the effect of hydrogen on the toughness of Zircaloy-2 by instrumented drop weight impact testing. $\mathrm{J}$ Nucl Mater 2006;350:310-9.

58. Gou Y., Li Y., Liu Y., Chen H., Ying S., Evaluation of a delayed hydride cracking in $\mathrm{Zr}-2.5 \mathrm{Nb}$ CANDU and RBMK pressure tubes. Mater Design 2009;30:1231-5.

59. Shavkunov S. P., Tolkachev A. B., Electrochemical Hydrogen Evolution at a Single-Crystal Zirconium Face in Sulfuric Acid Solutions. Russ J Electrochem 2002;38:714-9.

60. Bertolino G., Meyer G., Perez Ipiña J., In situ crack growth observation and fracture toughness measurement of hydrogen charged Zircaloy-4. J Nucl Mater 2003;322:57-65.

61. Szoka A., Gajowiec G., Serbinski W., Zielinski A., Effect of surface state and stress on an oxidation of the zircaloy-2 alloy. Intl J Manag Inform Techn Eng 2016;4:55-64.

62. Siripurapu R. K., Szpunar B., Szpunar J. A., Molecular Dynamics Study of Hydrogen in $\alpha-$ Zirconium. Intl J Nucl Energy 2014; International Journal of Nuclear Energy 2014;2014: Article ID 912369, six pages. 